\title{
ROLE OF WORK-FAMILY ENRICHMENT IN IMPROVING JOB SATISFACTION
}

\author{
${ }^{1} \mathrm{Ng}$ Swee Fung, ${ }^{2}$ Aminah Ahmad and ${ }^{3}$ Zoharah Omar \\ ${ }^{1,3}$ Department of Professional Development and Continuing Education, \\ Faculty of Educational Studies, \\ ${ }^{2}$ Institute for Social Science Studies, Putra Infoport, \\ Universiti Putra Malaysia, 43400 Serdang, Selangor Darul Ehsan, Malaysia
}

Received 2013-10-03; Revised 2013-10-22; Accepted 2013-12-07

\begin{abstract}
The role of work-family enrichment in improving job satisfaction has been given little attention. In this study a mediation model was tested which includes work-family enrichment as the mediator, job characteristics (job autonomy and job involvement) as antecedent factors and job satisfaction as the outcome. Data were gathered from 280 public secondary school teachers in Malaysia using selfadministered questionnaires. Work-family enrichment partially mediated the relationships between job characteristics and job satisfaction. The results contribute towards understanding how work-family enrichment could help improve job satisfaction.
\end{abstract}

Keywords: Work-Family Enrichment, Job Autonomy, Job Involvement, Job Satisfaction, Teacher

\section{INTRODUCTION}

Studies on the interface between work and family roles have the tendency to focus on the negative side of the interface, that is work-family conflict and studies on the positive side of work-family interface are relatively lacking (Brough and Kalliath, 2009; Aminah and Noryati, 2011). However, there have been a growing number of researchers who have recognized the positive side of this interface (Greenhaus and Powell, 2006; Noraani et al., 2011; Wayne et al., 2004). Researchers have used different labels to indicate the positive side of this interface, including work-family enhancement (Ruderman et al., 2002), enrichment (Carlson et al., 2006; Greenhaus and Powell, 2006; McNall et al., 2010b), facilitation (Wayne et al., 2004; Noraani et al., 2011) and positive spillover (Grzywacz and Marks, 2000; Hanson et al., 2006). Some researchers have used these labels interchangeably whereas others argued that the constructs, although related, are distinct constructs. This present study uses work-family enrichment since this term has been commonly used among researchers in investigating this positive interface (McNall et al., 2010a). Greenhaus and Powell (2006) defined workfamily enrichment as "the extent to which experience in one role improves the quality of life namely performance or affect, in the other role". Performing a job enriched with characteristics such as autonomy and involvement could increase perceived control over work-family matters as well gain benefits from job involvement that could enhance an individual's functioning as an efficient worker and family member (Innstrand et al., 2010; Aryee et al., 2005).

Besides the attention paid to job characteristics as antecedents of work-family enrichment, there is a growing interest on the consequences of enrichment including job satisfaction (Aryee et al., 2005; Balmforth and Gardner, 2006; Van Steenbergen et al., 2007; Wayne et al., 2004). Despite the growing interest, few researchers have focused on the mediating role of work-family enrichment in studies on job attitudes (Baral and Bhargava, 2010; McNall et al., 2010a), since workfamily enrichment as a field of study is still at its infancy Corresponding Author: Aminah Ahmad, Institute for Social Science Studies, Putra Infoport,

Universiti Putra Malaysia, 43400 Serdang, Selangor Darul Ehsan,

Malaysia Tel: +60389471871 Fax: +60389471856 
stage (Carlson et al., 2011; Shockley and Singla, 2011). Previously, most of the studies on work-family enrichment have been conducted in Western countries and far too little attention has been paid to examine work-family enrichment in Malaysia (Noraani et al., 2011). Additionally, the interface between work and family roles among teachers has rarely been examined (Cinamon and Rich, 2005). Recognizing this need, we conducted a study to examine the role of work-family enrichment as a mediator in the relationships between job characteristics and job satisfaction among Malaysian secondary school teachers.

\subsection{Literature Review \\ 1.1.1. Job Autonomy and Job Satisfaction}

The job characteristics model argues that an employee having a job with intrinsically motivating characteristics is more satisfied with their jobs (Hackman and Oldham, 1976). One of the core job characteristics is job autonomy which is the degree to which one has control and discretion over how to conduct one's job (Voydanoff, 2004). Individuals who are given the freedom to decide when, where and how they should do their jobs are more satisfied with their jobs (Clark, 2001). A significant relationship between job autonomy and job satisfaction in a sample of teachers (Skaalvik and Skaalvik, 2010) and among frontline employees (Yang, 2010) has been reported. Similar findings have been reported by Thompson and Prottas (2005). Studies done by Khalid et al. (2011) found that there was a significant relationship between autonomy and job satisfaction. Based on previous research findings we tested the following hypothesis:

H1a: There is a positive relationship between job autonomy and job satisfaction.

\subsection{Job Autonomy and Work-Family Enrichment}

Individuals having jobs with more autonomy reported higher level of work-family facilitation (Butler et al., 2005; Grzywacz and Butler, 2005; Grzywacz and Marks, 2000). Similarly, Voydanoff (2004) found that an enabling resource such as autonomy is related to workfamily facilitation. Autonomy is associated with resources including initiative, time-management skills and self-confidence (Voydanoff, 2004) and if applied to family activities, may contribute to work-family enrichment (Baral and Bhargava, 2008). Innstrand et al. (2010) investigated the impact of job autonomy on workfamily facilitation among people living in different family structures namely families of two parents, single parent, childless couples and singles in Norway. They found that job autonomy was positively related to work-family facilitation regardless of the types of family structures. A longitudinal study on work-family enrichment by Siu et al. (2010) has shown that increased level of job autonomy results in higher level of work-family enrichment. Contradictory results have been found in other studies (Andreassi and Thompson, 2007; Beham et al., 2011). Despite these contradictory results, most empirical evidences tend to support this autonomy-enrichment relationship and the following hypothesis was tested:

H1b: There is a positive relationship between job autonomy and work-family enrichment.

\subsection{Job Involvement and Job Satisfaction}

Job involvement is defined as the degree to which one is cognitively preoccupied with, engaged in and concerned with one's present job (Paullay et al., 1994). Research findings support the notion that greater job involvement lead to greater job satisfaction in different samples of workers. Adam et al. (1996) found that a higher level of job involvement led to greater job satisfaction among managers, health care workers, educators and clerical workers. Similar findings were reported in studies conducted on public elementary school teachers (Ting, 2011), pharmacists and accountants (Van Wyk et al., 2003), health volunteers ( $\mathrm{Li}$ et al., 2007), as well as correctional staff (Griffin et al., 2010).

Based on previous research findings, it is expected that an employee who is more preoccupied or engaged in his or her job would experience greater job satisfaction and the following hypothesis was tested:

H2a: There is a positive relationship between job involvement and job satisfaction.

\subsection{Job Involvement and Work-Family Enrichment}

The work and family involvement linkage offers a stronger support for a negative perspective than for a positive perspective as high involvement in a role is usually associated with a lower level of involvement in another role (Greenhaus and Parasuraman, 1999). However, the increased involvement in job provides skills, behaviors and positive moods which can be beneficial in another role (Wayne et al., 2004). The WFE scale by (Carlson et al., 2006) captures how involvement in family roles benefit from involvement in work roles through development (e.g., skills, knowledge, behaviors), positive affect (e.g., moods, attitude) and capital resources (e.g., security, confidence) derived from involvement in work. 
Although studies on the association between job involvement and work-family enrichment are scarce, a study by Aryee et al. (2005) indicated that job involvement was linked to work-family facilitation $(\beta=$ $0.23, \mathrm{p}<0.01)$ among full-time employed parents working in the financial services, manufacturing and telecommunications industries in India. Hence, based on the findings of this study and the assertion by earlier researchers that individuals performing family roles benefit from involvement in work roles through development, positive affect and capital resources derived from the latter, the following hypothesis was tested:

$\mathrm{H} 2 \mathrm{~b}$ : There is a positive relationship between job involvement and work-family enrichment.

\subsection{Work-Family Enrichment and Job Satisfaction}

One of the outcomes of work-family enrichment is job satisfaction. Several studies have examined the relationship between enrichment and job satisfaction. A study by Russo and Buonocore (2012) on nursing staff has shown that job satisfaction is an important consequence of work-family enrichment. A significant relationship between work-family enrichment and job satisfaction in a sample of employed parents was also reported by (Aryee et al., 2005; Hill, 2005; Lu et al., 2009). A longitudinal study of individuals from different organizations revealed that an increase in the level of work-family enrichment results in a higher level of job satisfaction (Lu, 2011). Based on previous research findings, it is expected that a higher intensity of workfamily enrichment lead to greater job satisfaction and the following hypothesis was tested:

H3: There is a positive relationship between workfamily enrichment and job satisfaction.

\subsection{Work-Family Enrichment as a Mediator}

The mediation model was grounded on the theory of Conservation of Resources (COR) Hobfoll (1989), the model of work-family enrichment (Greenhaus and Powell, 2006) and the social exchange theory (Blau, 1964). The COR theory proposes that to reduce stress individuals tend to acquire and maintain resources. Resources include objects, personal characteristics, conditions, energies and social support. This study used the COR theory to understand the relationship between job factors and job satisfaction. Job autonomy and job involvement are resources and resources gained may reduce the experience of stress such as job dissatisfaction. Resource generation is essential to the enrichment process
(Friedman and Greenhaus, 2000). Greenhaus and Powell (2006) model, there are five kinds of resources that may be acquired in a role to improve performance in the other role. These resources include skills and perspectives (e.g., multitasking skills, respecting individual differences), psychological and physical resources (e.g., optimism, self-efficacy), social-capital resources (networking, information), flexibility (e.g., flexible work arrangements) and material resources (e.g., salary, gifts) enable improved performance in the other role. Going beyond the enrichment process, the social exchange theory (Blau, 1964) is used to further understand the relationship between enrichment and work-related outcomes such as job satisfaction. Applying this to the work-family interface and its outcome, when employees perceive their organizations are helping them in managing their work and family roles, the employees would be expected to attribute those benefits to the source and reciprocate with positive attitudes at work, such as satisfaction with work (McNall et al., 2010a).

Based on the theory of Conservation of Resources (COR), the model of work-family enrichment, the social exchange theory and previous research findings, we predict that changes in the level of job resources could lead to changes in the level of work-family enrichment which in turn could lead to changes in the level of job satisfaction and thus the following hypotheses were tested:

H4a: Work-family enrichment mediates the relationship between job autonomy and job satisfaction

H4b: Work-family enrichment mediates the relationship between job involvement and job satisfaction

\section{MATERIALS AND METHODS}

\subsection{Sample and Procedure}

A two-stage sampling procedure was adopted. The schools were randomly selected from the list of names of secondary schools in the Bangsar Zone of Kuala Lumpur Federal Territory, Malaysia to represent all the secondary schools in the zone. Simple random sampling was used to select teachers from the selected secondary schools. Data were collected using selfadministered questionnaires through the drop and collect method. In line with prior studies (Grzywacz and Marks, 2000; Siu et al., 2010; Van Steenbergen et al., 2007), this study did not limit the sampling to married employees with or without children because this would reflect too narrow a conceptualization of the family. However, the sample did not include teachers undergoing practical training or replacement teachers 
and teachers who had serious illness. The final sample included 280 teachers (218 females and 62 males), resulting in a response rate of approximately 93\%. The sample had a mean age of 36.51 years $(\mathrm{SD}=8.12$, range $=24-57)$ and mean job tenure of 11.36 years $(\mathrm{SD}=$ 8.21). About three-quarters $(79.6 \%)$ of the total number of teachers were married. In terms of educational attainment, $87.5 \%$ had a bachelor's degree and the rest had earned a postgraduate degree.

\subsection{Measurement}

Work-family enrichment: work-family enrichment was measured using the nine-item work-to-family enrichment scale by (Carlson et al., 2006), with three items measuring work-to-family development (e.g., "My involvement in work helps me to understand different viewpoints and this helps me be a better family member"), three items capturing work-to-family affect (e.g., "My involvement in work puts me in a good mood and this helps me be a better family member") and three items measuring work-to-family capital (e.g.,, "My involvement in work helps me feel personally fulfilled and this helps be a better family member"). Five-point scaled response options ranging from strongly disagree (1) to strongly agree (5) were used. The reliability coefficients (alpha) for this work-family enrichment scale were 0.73 for the work-to-family development component, 0.91 for work-to-family affect, 0.90 for work-to-family capital and 0.92 for the overall nine-item scale as reported by (Carlson et al., 2006).

Job autonomy: Job autonomy was measured using a scale by Sims et al. (1976) and used by Weber and Weber (2001). Five-point response options ranging from 'strongly disagree' to 'strongly agree' were used for each statement. Higher scores reflect higher reported levels of autonomy. Examples of items are "I am given the freedom to do my own work" and "I have control over the pace of my work". The reliability of the scale from a study by Weber and Weber (2001) was 0.89 .

Job involvement: Job Involvement was measured using the ten-item Job Involvement Questionnaire (Kanungo, 1982). Examples of items are "The most important things that happen to me involve my present job" and "I live, eat and breathe my job". An internal consistency reliability of 0.87 was reported by Kanungo (1982).

Job satisfaction: Job satisfaction was measured using six items adapted from the instrument developed by Clark (2001). The teachers were requested to respond using five-point scaled response options ranging from strongly disagree (1) to strongly agree (5). Sample items include "I find my activities at work to be personally meaningful" and "I am very satisfied with this job". An internal consistency reliability of 0.91 was reported by (Clark, 2001).

\subsection{Data Analysis}

Data were analyzed using descriptive statistical, correlational and inferential statistical analyses. Means and standard deviations were used to describe the variables. The correlational coefficients between variables were computed using the Maximum Likelihood Estimation method. The Structural Equation Modeling (SEM) technique which integrates the measurement and structural models was utilized to examine the direct and indirect relationships among variables. The 280 respondents for this study met the requirement (minimum of 200) for using SEM (Hoe, 2008).

\section{RESULTS}

Results of correlation analyses show that employees who score high in job autonomy $(\mathrm{r}=0.43, \mathrm{p}<0.001)$ and job involvement $(r=0.38, \mathrm{p}<0.001)$ report high levels of work-family enrichment and employees who score high in job autonomy $(r=0.50, p<0.001)$ and job involvement $(\mathrm{r}=0.56, \mathrm{p}<0.001)$ report high levels of job satisfaction (Table 1). Further, the results show that those who report high levels of work-family enrichment also report high levels of job satisfaction $(\mathrm{r}=0.75, \mathrm{p}<0.001)$. The alpha value for every scale which ranges from 0.83 to 0.95 exceeds the 0.70 threshold for an acceptable reliability coefficient (Hair et al., 2010) suggests an adequate internal consistency of the variables. The Average Variance Extracted (AVE) values which ranged from 0.500 to 0.739 indicate that all the latent variables have high convergent validities (Hair et al., 2010).

The goodness-of-fit indices of the measurement model with the fit indices $\left(\chi^{2}=337.658, \chi^{2} / \mathrm{df}=2.638\right.$, AGFI $=$ $0.839, \mathrm{GFI}=0.879, \mathrm{CFI}=0.931, \mathrm{RMSEA}=0.077, \mathrm{TLI}=$ $0.917, \mathrm{IFI}=0.931)$ have three indices (CFI, TLI and IFI) that exceed the cutoff value of 0.90 . The RMSEA value falls within 0.03 and 0.08 which is the recommended range of acceptable values (Hair et al., 2010).

Alternative structural models were tested against each other to test the hypotheses. The mediation model was compared to a competing indirect model in which all path coefficients from job factors to job satisfaction were constrained to zero and to a competing direct model in which all path coefficients to and from workfamily enrichment were constrained to zero. As shown in Table 2, the mediation model has a better fit to the data compared to the indirect and direct models. The values 
of CFI, IFI and TLI for the mediation model were all above 0.90 and the RMSEA value is below 0.08 .

The path and parameter estimates of the mediation, indirect and direct models are presented in Table 3. All estimated path coefficients are significant. The path coefficients in the direct model indicate that job autonomy $(\beta=0.34, \mathrm{p}<0.001)$ and job involvement $(\beta=$ $0.44, \quad \mathrm{p}<0.001)$ are significantly related to job satisfaction, thus satisfying the direct effect condition and supporting Hypotheses $1 \mathrm{a}$ and $2 \mathrm{a}$. In addition, the path coefficients indicate that job autonomy $(\beta=0.34$, $\mathrm{p}<0.001)$ and job involvement $(\beta=0.26, \mathrm{p}<0.001)$ are significantly related to work-family enrichment. These results provide support for Hypotheses $1 b$ and $2 b$. Hypothesis 3 is supported as evidenced by the significant relationship between work-family enrichment and job satisfaction $(\beta=0.58, \mathrm{p}<0.001)$.

To address hypothesis 4 , the causal step approach to test mediation as proposed by (Baron and Kenny, 1986) was used. The results suggest that a partial mediation is established since the direct effects of job autonomy on job satisfaction $(\beta=0.14, p=0.006)$ and job involvement on job satisfaction $(\beta=0.29, \mathrm{p}<0.001)$ decrease but remain significant upon the addition of work-family enrichment acting as the mediator in the model. Hence, Hypotheses $4 \mathrm{a}$ and $4 \mathrm{~b}$ were supported.

Job autonomy and job involvement jointly explained $25 \%\left(\mathrm{R}^{2}=0.25\right)$ of the variance in work-family enrichment (Fig. 1). Overall, 67\% of the variance in job satisfaction was accounted for by job autonomy, job involvement and work-family enrichment.

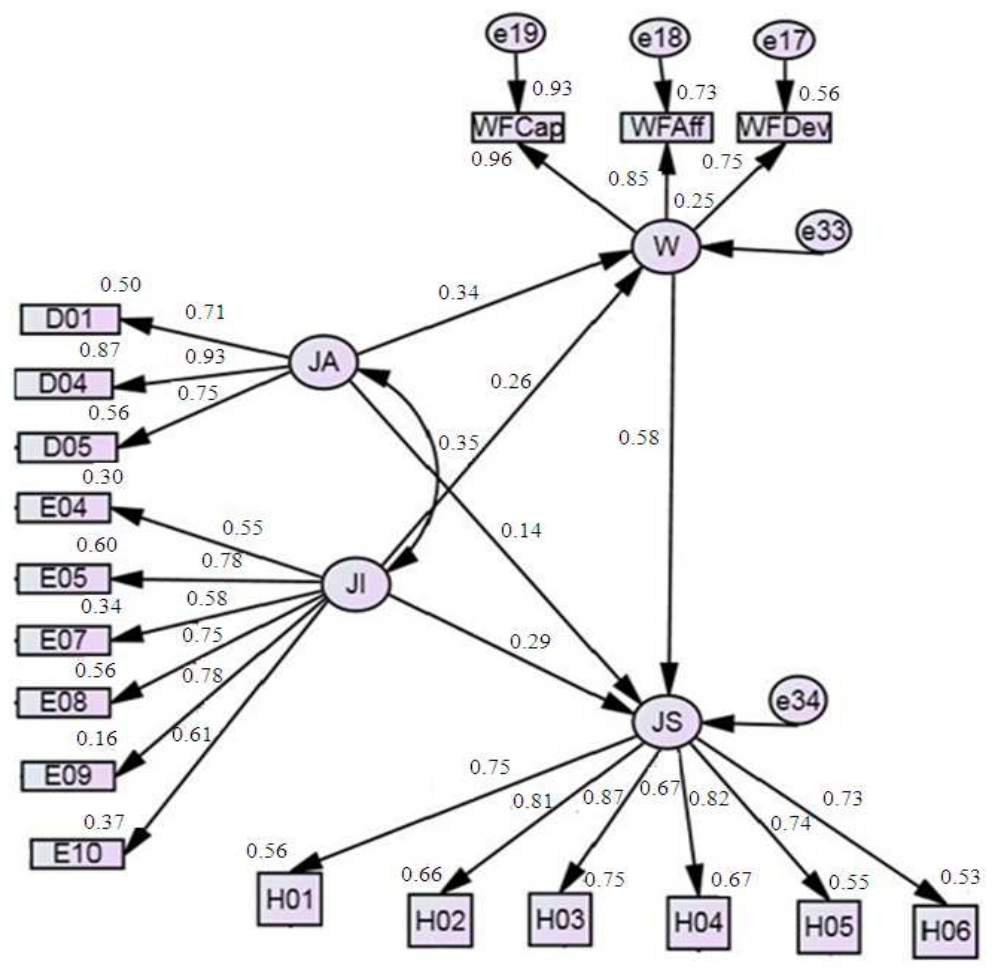

Note: JA Job Autonomy; JI = Job Involvement; W = Work-Family Enrichment; JS = Job Satisfaction

Fig. 1. Estimated path coefficients of the mediation model

Table 1. Descriptive statistics, reliability coefficients, AVE estimates and correlation coefficients

\begin{tabular}{llllllll}
\hline Variables & Mean & SD & $\alpha$ & JA & JI & W & JS \\
\hline JA & 3.22 & 0.78 & 0.83 & $(0.64)$ & & \\
JI & 3.16 & 0.66 & 0.83 & $0.35^{* * *}$ & $(0.50)$ & \\
W & 3.79 & 0.65 & 0.95 & $0.43^{* * *}$ & $0.38^{* * *}$ & $(0.74)$ \\
JS & 3.74 & 0.66 & 0.91 & $0.50^{* * *}$ & $0.56^{* * *}$ & $0.75^{* * *}$ & $(0.62)$ \\
\hline
\end{tabular}

Note: $* * * \mathrm{p}<0.001 ; \alpha=$ Cronbach alpha reliability values; AVE estimates are presented in parentheses; JA = Job Autonomy; JI = Job Involvement; W = Work-Family Enrichment; JS = Job Satisfaction 
Ng Swee Fung et al. / American Journal of Applied Sciences 11 (1): 96-104, 2014

Table 2. Model fit summary and structural model comparisons

\begin{tabular}{lllllllll}
\hline Model & $\chi^{2}$ & $\chi^{2} / \mathrm{df}$ & AGFI & GFI & CFI & RMSEA & TLI & IFI \\
\hline MM & 337.658 & 2.638 & 0.839 & 0.879 & 0.931 & 0.077 & 0.917 & 0.931 \\
IM & 383.055 & 2.947 & 0.830 & 0.871 & 0.916 & 0.084 & 0.901 & 0.917 \\
DM & 527.018 & 4.023 & 0.785 & 0.835 & 0.869 & 0.104 & 0.847 & 0.870 \\
\hline
\end{tabular}

Note: $\mathrm{MM}=$ Mediation Model, $\mathrm{IM}=$ Indirect Model, DM = Direct Model

Table 3. Standardized path coefficients

\begin{tabular}{|c|c|c|c|c|}
\hline $\begin{array}{l}\text { Dependent } \\
\text { Variables }\end{array}$ & $\begin{array}{l}\text { Independent } \\
\text { variables }\end{array}$ & $\begin{array}{l}\text { Mediation } \\
\text { model }\end{array}$ & $\begin{array}{l}\text { Indirect } \\
\text { model }\end{array}$ & $\begin{array}{l}\text { Direct } \\
\text { model }\end{array}$ \\
\hline $\mathrm{W}$ & JA & $0.34 * * *$ & $0.36 * * *$ & \\
\hline W & JI & $0.26 * * *$ & $0.29 * * *$ & \\
\hline JS & W & $0.58 * * *$ & $0.77 * * *$ & \\
\hline JS & JA & $0.14 * *$ & & $0.34 * * *$ \\
\hline JS & JI & $0.29 * * *$ & & $0.44 * * *$ \\
\hline
\end{tabular}

\section{DISCUSSION}

The findings of this study indicate that teachers with job autonomy experience higher levels of job satisfaction. The findings that job autonomy is a significant and positive predictor of job satisfaction has also been reported by (Skaalvik and Skaalvik, 2010; Yang, 2010) as well as other researchers (Clark, 2001; Kreis and Brookopp, 1986; Thompson and Prottas, 2005). With regard to job autonomy and its association with work-family enrichment, this study found that an increase in job autonomy by teachers led to an increase in work-family enrichment. These findings are consistent with the findings of (Siu et al., 2010; Innstrand et al., 2010). Similar findings have been reported by (Butler et al., 2005; Grzywacz and Butler, 2005; Grzywacz and Marks, 2000; Voydanoff, 2004).

The significant relationship between job involvement and job satisfaction shows that teachers with high levels of psychological involvement in their study are preoccupied with their study that they devote an excessive amount of effort and energy to their study because they recognize that work can satisfy their needs and hence experience greater job satisfaction. This is consistent with the findings of other researchers (Adam et al., 1996; Aryee et al., 2005; Ting, 2011). The significant relationship between teachers' job involvement and work-family enrichment is in line with the findings of (Aryee et al., 2005) and support the assertion made by (Greenhaus and Parasuraman, 1999; Wayne et al., 2004; Carlson et al., 2006) that involvement at work provides an opportunity to learn new skills, gain knowledge and various work resources that could be transferred and utilized in the family domain.

Teachers who reported higher intensities of workfamily enrichment tended to experience higher levels of job satisfaction. The significant relationship between work-family enrichment and job satisfaction is consistent with the findings of previous researchers (Aryee et al., 2005; Lu, 2011; Lu et al., 2009; Russo and Buonocore, 2012).

The results on mediating effects of work-family enrichment in the relationships between job characteristics and job satisfaction indicate that teachers with more job autonomy and job involvement tend to experience higher intensities of enrichment which would led to greater job satisfaction.The findings reveal that the COR theory (Hobfoll, 1989), the model of work-family enrichment (Greenhaus and Powell, 2006) and the social exchange theory (1964) could help explain the model. Based on the COR theory (Hobfoll, 1989), teachers tend to preserve, protect and expand their resources to reduce job dissatisfaction. The resources gained at work can improve the quality of family life. Teachers who perceive good treatment from their organizations tend to reciprocate with positive attitudes at work such as job satisfaction and this is in line with the social exchange theory (Blau, 1964).

The findings of this study have important implications for employers and employees. Employers should look into the possibility of designing training programs to assist teachers to take more control of events in their work situations. This could be a fruitful effort toward improving employees' work-family enrichment. This study indicates that involvement in work roles should not be viewed as a hindrance, since it can also benefit employees at home. Involvement in work roles provides opportunities to acquire resources that could benefit involvement in family roles. Besides, this study significantly contributes to the growing body of literature on work-family studies and positive psychology.

There are several limitations in this study that should be acknowledged. First, the sample size is restricted to Malaysian school teachers and hence, the results of the study may not be generalized to other occupational populations and cultures. Second, our 
sample consisted of a higher proportion of female than male teachers that could have influenced the results and hence, there is a possibility that the findings may not be similar in a male-dominated setting. Third, the crosssectional non-experimental design of the study restricts the inference of causality from the findings. For instance, it is possible that high job satisfaction may lead to higher perceptions of work-family enrichment. Thus, future researchers may benefit from longitudinal studies (Casper et al., 2007; Kelly et al., 2008) that examine the antecedents and outcomes of enrichment over time, which could assist in exploring these relationships.

\section{CONCLUSION}

To conclude, this study underscores the importance of examining the benefits of participating in work role and demonstrates how experience in work role, could improve performance in family role. Work-family enrichment serves as a potential mechanism through which job characteristics could improve job satisfaction. An employee with more job autonomy and who is more involved in his or her job tends to experience higher intensity of work-family enrichment which would in turn increase the level of job satisfaction.

\section{REFERENCES}

Adam, G.A., L.A. King and D.W. King, 1996. Relationships of job and family involvement, family social support and work-family conflict with job and life satisfaction. J. Applied Psychol., 81: 411-420. DOI: $10.1037 / 0021-9010.81 .4 .411$

Aminah, A. and N. Noryati, 2011. Impact of dispositional factors and work-family conflict on job satisfaction among single mother employees. Am. J. Applied Sci., 8: 1107-1115. DOI: 10.3844/ajassp.2011.1107.1115

Andreassi, J.K. and C.A. Thompson, 2007. Dispositional and situational sources of control: Relative impact on work-family conflict and positive spillover. J. Managerial Psychol., 22: 722-740. DOI: 10.1108/02683940710837697

Aryee, S., E.S. Srinivas and H.H. Tan, 2005. Rhythms of life: Antecedents and outcomes of work-family balance in employed parents. J. Applied Psychol., 9: 132-146. DOI: 10.1037/0021-9010.90.1.132

Balmforth, K. and D. Gardner, 2006. Conflict and facilitation between work and family: Realizing the outcomes for organizations. New Zealand J. Psychol., 35: 69-76.
Baral, R. and S. Bhargava, 2008. Work-family enrichment as a mediator between organizational interventions for work-life balance and job outcomes. J. Managerial Psychol., 25: 274-300. DOI: $10.1108 / 02683941011023749$

Baral, R. and S. Bhargava, 2010. Work-family enrichment as a mediator between organizational interventions for work-life balance and job outcomes. J. Managerial Psychol., 25: 274-300. DOI: $10.1108 / 02683941011023749$

Baron, R.M. and D.A. Kenny, 1986. The moderatormediator variable distinction in social psychological research: Conceptual, strategic and statistical considerations. J. Personality Social Psychol., 51: 1173-1182. DOI: 10.1037/0022-3514.51.6.1173

Beham, B., S. Dronic and P. Prag, 2011. Work demands and rosurces and the work-fmaily interface: Testing a salience model on German service sector employees. J. Vocat. Behav., 78: 110-122. DOI: 10.1016/j.jvb.2010.07.008

Blau, P.M., 1964. Exchange and Power in Social Life. 1st Edn., Wiley, ISBN: 1412823153, pp: 352.

Brough, P. and T. Kalliath, 2009. Work-family balance: Theoretical and empirical advancements. J. Organ. Behav., 30: 581-585. DOI: 10.1002/job.618

Butler, A.B., J.G. Grzywacz, B.L. Bass and K.D. Linney, 2005. Extending the demands-control model: A daily diary study of job characteristics, work-family conflict and work-family facilitation. J. Occupat. Org. Psychol., 78: 155-169. DOI: 10.1348/096317905X40097

Carlson, D.S., K.M. Kacmar, J.H Wayne and J.G. Grzywacz, 2006. Measuring the positive side of the work-family interface: Development and validation of a work-family enrichment scale. J. Vocat. Behav., 68: 131-164. DOI: 10.1016/j.jvb.2005.02.002

Carlson, D.S., M. Ferguson, K.M. Kacmar, J.G. Grzywacz and D. Whitten et al., 2011. Pay it forward: The positive crossover effects of supervisor work-family enrichment. J. Manage., 37: 770-789. DOI: $10.1177 / 0149206310363613$

Casper, W.J., D. Weltman and E. Kwesiga, 2007. Beyond family-friendly: The construct and measurement of singles-friendly work cultures. J. Vocat. Behav., 70: 478-501. DOI: 10.1016/j.jvb.2007.01.001

Cinamon, R.G. and Y. Rich, 2005. Work-family conflict among female teachers. Teach. Teacher Educ., 21: 365-337. DOI: 10.1016/j.tate.2004.06.009

Clark, S.C., 2001. Work cultures and work/family balance. J. Vocat. Behav., 58: 348-365. DOI: 10.1006/jvbe.2000.1759 
Friedman, S.D. and J.H. Greenhaus, 2000. Work and Family-Allies or Enemies? What Happens When Business Professionals Confront Life Choices. 1st Edn., Oxford University Press, ISBN-10: 0198027257, pp: 288.

Greenhaus, J.H. and G.N. Powell, 2006. When work and family are allies: A theory of work-family enrichment. Acad. Manage. Rev., 31: 72-92. DOI: 10.5465/AMR.2006.19379625

Greenhaus, J.H. and S. Parasuraman, 1999. Research on Work, Family and Gender: Current Status and Future Directions. In: Handbook of Gender and Work, G.N. Powell, (Ed.), SAGE Publications, Thousand Oaks, ISBN-10: 0761913556, pp: 391-412.

Griffin, M.L., N.L. Hogan, E.G. Lambert, K.A. TuckerGail and D.N. Baker, 2010. Job involvement, job stress, job satisfaction and organizational commitment and the burnout of correctional staff. Crim. Justice Behav., 37: 239-255. DOI: 10.1177/0093854809351682

Grzywacz, J.G. and A.B. Butler, 2005. The impact of job characteristics on work-to-family facilitation: Testing a theory and distinguishing a construct. J. Occupat. Health Psychol., 10: 97-109. DOI: 10.1037/1076-8998.10.2.97

Grzywacz, J.G. and N.F. Marks, 2000. Reconceptualizing the work-family interface: A ecological perspective on the correlates of positive and negative spillover between work and family. J. Occupat. Health Psychol., 5: 111-126. DOI: 10.1037/1076-8998.5.1.111

Hackman, J.R. and G.R. Oldham, 1976. Motivation through the design of work: Test of a theory. Organ. Behav. Hum. Perform., 16: 250-279. DOI: 10.1016/0030-5073(76)90016-7

Hair, J.F., W.C. Black, B.J. Babin and R.E. Anderson, 2010. Multivariate Data Analysis. 7th Edn., Pearson Education Inc., New Jersey, ISBN-10: 0138132631, pp: 785.

Hanson, G.C., L.B. Hammer and C.L. Colton, 2006. Development and validation of a multidimensional scale of perceived work-family positive spillover. J. Occupat. Health Psychol., 11: 249-265. DOI: 10.1037/1076-8998.11.3.249

Hill, E.J., 2005. Work-family facilitation and conflict, working fathers and mothers, work-family stressors and support. J. Family Issues, 26: 793-819. DOI: 10.1177/0192513X05277542

Hobfoll, S.E., 1989. Conservation of resources: A new attempt at conceptualizing stress. Am. Psychol., 44: 513-524. DOI: 10.1037/0003-066X.44.3.513
Hoe, S.L., 2008. Issues and Procedures in adopting structural equation modeling technique. J. Applied Q. Meth., 3: 76-83.

Innstrand, S.T., E.M. Langballe, G.A. Espnes, O.G. Aasland and E. Falkum et al., 2010. Work-home conflict and facilitation across four different family structures in Norway. Community Work Family, 1: 1-20. DOI: 10.1080/13668800903314341

Kanungo, R.N., 1982. Measurement of job and work involvement. J. Applied Psychol., 67: 341-349. DOI: 10.1037/0021-9010.67.3.341

Kelly, E.L., E.E. Kossek, L.B., Hammer, M. Durham and J. Bray et al., 2008. Getting there from here: Research on the effects of work-family initiatives on work-family conflict and business outcomes. Acad. Manage. Annals, 2: 305-349. DOI: 10.1080/19416520802211610

Khalid, K., H.M. Salim, S.P. Loke and K. Khalid, 2011. The key components of job satisfaction in Malaysia water utility industry. J. Soc. Sci., 7: 550-556. DOI: 10.3844/jssp.2011.550.556

Kreis, K. and D.Y. Brookopp, 1986. Autonomy: A component of teacher job satisfaction. Education, 107: 110-115.

Li, I.C., M.C. Lin and C.M. Chen, 2007. Relationship between personality traits, job satisfaction and job involvement among Taiwanese community health volunteers. Public Health Nurs., 24: 274-282. DOI: 10.1111/j.1525-1446.2007.00634.x

Lu, J.F., O.L. Siu, P.E. Spector and K. Shi, 2009. Antecedents and outcomes of a fourfold taxonomy of work-family balance in Chinese employed parents. J. Occupat. Health Psychol., 14: 182-192. DOI: $10.1037 / \mathrm{a} 0014115$

Lu, L., 2011. A Chinese longitudinal study on work/family enrichment. Career Dev. Int., 16: 385400. DOI: $10.1108 / 13620431111158797$

McNall, L.A., A.D. Masuda and J.M. Nicklin, 2010a. Flexible work arrangement, job satisfaction and turnover intentions: The mediating role of work-tofamily enrichment. J. Psychol., 144: 61-81. DOI: 10.1080/00223980903356073

McNall, L.A., J.M. Nicklin and A.D. Masuda, 2010b. A meta-analytic review of the consequences associated with work-family enrichment. J. Bus. Psychol., 25: 381-396. DOI: 10.1007/s10869-009-9141-1

Noraani, M., A. Aminah, U. Jegak and I. Khairuddin, 2011. Work-family facilitation and family satisfaction as mediators in the relationship between job demands and intention to stay. Asian Soc. Sci., 7: 142-153. DOI: $10.5539 /$ ass.v7n6p142 
Paullay, I.M., G.M. Alliger and E.F. Stone-Romero, 1994. Construct validation of two instruments designed to measure job involvement and work centrality. J. Applied Psyhcol., 79: 224-228. DOI: 10.1037/0021-9010.79.2.224

Ruderman, M.N., P.J. Ohlott, K. Panzer and S.N. King, 2002. Benefits of multiple roles for managerial women. Acad. Manage. J., 45: 369-386. DOI: $10.2307 / 3069352$

Russo, M. and F. Buonocore, 2012. The relationship between work-family enrichment and nurse turnover. J. Managerial Psychol., 27: 216-236. DOI: 10.1108/02683941211205790

Shockley, K.M. and N. Singla, 2011. Reconsidering work-family interactions and satisfaction: A metaanalysis. J. Manage., 37: 861-886. DOI: 10.1177/0149206310394864

Sims, H.P., A.D. Szilagy and R.T. Keller, 1976. The measurement of job characteristics. Acad. Manage. J., 19: 195-212. DOI: 10.2307/255772

Siu, O.L., J.F. Lu, P. Brough, C.Q. Lu and A.B. Bakker et al., 2010. Role resources and work-family enrichment: The role of work engagement. J. Vocat. Behav., 77: 470-480. DOI: 10.1016/j.jvb.2010.06.007

Skaalvik, E.M. and S. Skaalvik, 2010. Teacher selfefficacy and teacher burnout: A study of relations. Teach. Teacher Educ., 26: 1059-1069. DOI: 10.1016/j.tate.2009.11.001

Thompson, C.A.K. and D.J. Prottas, 2005. Relationships among organizational family support, job autonomy, perceived control and employee well-being. J. Occupat. Health Psychol., 10: 100-118. DOI: 10.1037/1076-8998.10.4.100
Ting, S.C., 2011. The effect of internal marketing on organizational commitment: Job involvement and Job satisfaction as mediators. Educ. Admin. Q., 47: 353-382. DOI: 10.1177/0013161X10387589

Van Steenbergen, E.F., N. Ellemers and A. Mooijaart, 2007. How work and family can facilitate each other: Distinct types of work-family facilitation and outcomes for women and men. J. Occupat. Health Psychol., 12: 279-300. DOI: 10.1037/10768998.12.3.279

Van Wyk, V.R., A.B. Boshoff and F. Cilliers, 2003. The prediction of job involvement for pharmacists and accountants. SA J. Indust. Psychol., 29: 61-67. DOI: 10.4102/sajip.v29i3.118

Voydanoff, P., 2004. The effects of work demands and resources on work-to-family conflict and facilitation. J. Marriage Family, 66: 398-412. DOI: 10.1111/j.1741-3737.2004.00028.x

Wayne, J.H., N. Musisca and W. Fleeson, 2004. Considering the role of personality in the workfamily experience: Relationships of the big five to work-family conflict and facilitation. J. Vocat. Behav., 64: 108-130. DOI: 10.1016/S00018791(03)00035-6

Weber, P.S. and J.E. Weber, 2001. Changes in employee perceptions during organizational change. Leadership Organ. Dev. J., 22: 291-300. DOI: 10.1108/01437730110403222

Yang, J.T., 2010. Antecedents and consequences of job satisfaction in the hotel industry. Int. J. Hospit. Manage., 29: 609-619. DOI: 10.1016/j.ijhm.2009.11.002 